\title{
ASSESSMENT OF THE EFFECTIVENESS OF LUBRICATION OF TI-6AL-4V TITANIUM ALLOY SHEETS USING RADIAL BASIS FUNCTION NEURAL NETWORKS
}

\author{
Tomasz Trzepieciński ${ }^{a, *}$, MARCIN SzPUnAR $^{b}$ \\ ${ }^{a}$ Rzeszow University of Technology, Department of Materials Forming and Processing, al. Powst. Warszawy 8, \\ 35-959 Rzeszów, Poland \\ ${ }^{b}$ Rzeszow University of Technology, Doctoral School of Engineering and Technical Sciences at the Rzeszow \\ University of Technology, al. Powst. Warszawy 12, 35-959 Rzeszów, Poland \\ * corresponding author: tomtrz@prz.edu.pl
}

\begin{abstract}
The aim of the research presented in this article was to determine the value of the friction coefficient using a simple tribological test and to build an empirical model of friction with the use of radial basis function artifi-cial neural networks. The friction tests were carried out on a specially designed friction simulator that allows a sheet metal strip to be drawn between two fixed dies. The test materials were sheets of Ti-6Al-4V titanium alloy with a thickness of $0.5 \mathrm{~mm}$. The friction tests were carried out with variable contact forces of counter-samples with rounded surfaces and in various lubrication conditions. Mineral oils and bio-degradable oils with the addition of boric acid (5 wt \%) were tested. Based on the results of friction investigations, neural models of friction were built using RBF artificial neural networks. The good properties of the RBF network 2:2-35-1:1 were confirmed by a high value of the determination coefficient $\mathrm{R} 2=0.9984$ and a low value of the S.D. ratio equal to 0.0557. It was found that the COF value was the highest for the average values of both the nominal pressure and kinematic viscosity. Over the entire range of nominal pressures applied, SAE10W-40 engine oil ensured the most effective reduction of the COF. The COF value was the highest for the average values of both the nominal pressure and kinematic viscosity.
\end{abstract}

KEYWORDS: Artificial neural networks, coefficient of friction, friction, sheet metal forming, Ti-6Al-4V, titanium sheets.

\section{INTRODUCTION}

Sheet metal forming (SMF) is one of the most popular methods of obtaining finished products, especially in the automotive industry. The processes taking place in the contact zone in SMF are influenced by many factors, including the amount of normal pressures, the macro- and microgeometry of the contact interface, both the type and the viscosity of the lubricant, the kind of die and workpiece material, the topography of the sheet surface and tools, the dynamics of the loads, physicochemical phenomena on the contact surface and the processing temperature [1, 2]. The factors dependent on the technological parameters of the SMF process include the values of normal pressure and the sliding speed [3, 4]. The value of the coefficient of friction ( $\mathrm{COF}$ ) continuously changes during the forming process due to the flattening and wear of the roughness asperities on the tool surface [4, 5]. The appropriate selection of the process parameters determines the fabrication of a product with the required dimensional and shape accuracy.

Titanium sheets exhibit many problems in SMF. Depending on the structure existing at a room temperature, titanium alloys are divided into single-phase $\alpha$ alloys, two-phase $\alpha+\beta$ and single-phase $\beta$ alloys. Each group of these alloys is characterised by differ- ent mechanical and technological properties. Sheet metals made of $\alpha+\beta$ alloys are characterised by good mechanical properties, but have little susceptibility to plastic deformation. Intense adhesive wear, low abrasion resistance and high coefficients of friction are regarded as the adverse effects of the tribological behaviour of titanium sheets [6]. Mechanical sliding between titanium alloy and steel dies may lead to wear damage on the surface by disrupting the protective oxide layer [7. The basic wear mechanism in titanium alloys is abrasion followed by adhesion and transfer layer [8].

There are many friction tests used to simulate tribological phenomena in the different areas of drawpieces in SMF. The strip drawing test (SDT) is the basic tribological test to assess the friction phenomenon in the sheet metal forming process. The SDT is assigned to model the friction phenomenon between the punch and the drawpiece wall as well as between the sheet metal and the blankholder in the flange area of the drawpiece. This test consists in pulling a metallic strip of sheet metal placed between counter-samples with a rounded [2, 9] or flat [10, 11] shape. The parameters influencing the change of the $\mathrm{COF}$ are the minimal pressure, lubrication conditions, sliding speed and the use of sheets with different surface topographies [12]. The SDT can be used for testing the influence of the 
viscosity of the lubricant and the mechanical properties of the sheet metal on the value of the COF of coated and uncoated sheets 13 .

Physicochemical phenomena occurring in the contact zone depend on the materials of the friction pair and the chemical affinity of the bodies in contact. During the friction process, friction connections are created between surface asperities, which are destroyed during sliding [14, 15]. The value of COF is mainly determined by the shear strength of the friction connections. The type of the frictional connection depends on the materials of the friction pair, in particular their shear strength. The basic method of limiting the friction in plastic working is proper lubrication [16, 17]. The lubricant, when applied to the surface of a deformed material or tool, forms a thin layer that partially or completely separates the surfaces in contact. The basic properties of the lubricant include viscosity and surface free energy, which determine the performance of the lubricant under high unit pressures [18. Due to the large variety of conditions of plastic working processes, there are no universal lubricants. Each process requires a separate approach to the problem of lubrication and the use of an appropriate lubricant. In recent years, an attempt has been made to replace mineral oils with biodegradable vegetable oils to which have been added nanoparticles of various substances [11, 17, 19].

Due to the large number of factors that influence the friction phenomenon, it is often difficult to interpret the results without an appropriate empirical model in the form of nonlinear regression 20, Response Surface Methodology (RSM) 21, Multivariate Adaptive Regression Splines (MARS) polynomial response surface models [22] or neural networks (ANN) 23 25]. The mathematical models allow to explore mechanisms relating controllable input variables to observed outputs. ANNs are a tool enabling the building of linear and nonlinear models that solve complex classification and regression tasks [26, 27]. One of the basic advantages of neural networks is the fact that as a result of the learning process, the network can acquire the ability to predict output signals based on the observation of the training set.

In this paper, friction investigations using a strip drawing friction simulator have been carried out on 0.5-mm-thick Ti-6Al-4V titanium sheets. The effect of the friction test parameters on the coefficient of friction of the sheet metal have been analysed using radial basis function (RBF) artificial neural networks (ANN).

\section{MATERIAL AND METHODS}

Sheets of 0.5 -mm-thick Ti-6Al-4V titanium alloy are used as the test material. The chemical composition of Ti-6Al-4V titanium alloy is listed in Table 1 . The basic mechanical properties of Ti-6Al-4V titanium alloy are listed in Table 2 .

\begin{tabular}{cc}
\hline Element & wt. $\%$ \\
\hline $\mathrm{Al}$ & 5.5 \\
$\mathrm{~V}$ & 3.5 \\
$\mathrm{O}$ & $<0.2$ \\
$\mathrm{Fe}$ & $<0.3$ \\
$\mathrm{H}$ & $<0.0015$ \\
$\mathrm{C}$ & $<0.08$ \\
$\mathrm{~N}$ & $<0.05$ \\
$\mathrm{Ti}$ & remainder \\
\hline
\end{tabular}

TABle 1. Chemical composition of the Ti-6Al-4V titanium alloy examined (in wt. \%).

\begin{tabular}{lc}
\hline Property (unit) & Value \\
\hline Young's modulus (GPa) & 115 \\
Yield stress (MPa) & 880 \\
Ultimate tensile stress (MPa) & 950 \\
Elongation at break (\%) & 14 \\
Hardness (HB) & 334 \\
\hline
\end{tabular}

TABLE 2. Selected mechanical parameters of the Ti$6 \mathrm{Al}-4 \mathrm{~V}$ titanium alloy.

The measurement of the surface roughness parameters of as-received sheet metal was carried out using a Bruker Contour GT 3D optical measuring tool according to EN ISO 25178. The basic surface roughness parameters are as follows: average height of a selected area $S a=0.23 \mu \mathrm{m}$, maximum valley depth of the selected area $S v=1.10 \mu \mathrm{m}$, maximum peak height of the selected area $S p=1.14 \mu \mathrm{m}$, maximum height of the selected area $S z=2.03 \mu \mathrm{m}$.

The friction simulator (Fig. 1) which performs the SDT was mounted on a Zwick/Roell Z100 universal tensile testing machine. The frame of the device was mounted in the bottom grip of the machine. Sheet metal strips with a width of $w=18 \mathrm{~mm}$ were used as test material. The strips were drawn between fixed cylindrical countersamples. The frame of the friction simulator was mounted in the bottom grip of the testing machine while one end of the sheet metal strip was mounted in the upper grip of the tensile machine. The pressure of the rollers on the specimen was applied through a Teflon insert and a spring working in compression mode. The pressure of the spring on the countersamples was achieved by reducing its height as a result of tightening a screw. Six levels of nominal pressure, i.e. $75,96,112,127$, 139, $151 \mathrm{MPa}$, were considered. A set of rolls with an average surface roughness of $R a=0.32 \mu \mathrm{m}$ measured along the generating line of rolls was used in the tests.

The COF has been evaluated according to Eq. (1).

$$
\mu=\frac{F_{T}}{2 F_{C}}
$$

where $F_{T}$ is the friction force and $F_{C}$ is the clamping force. 


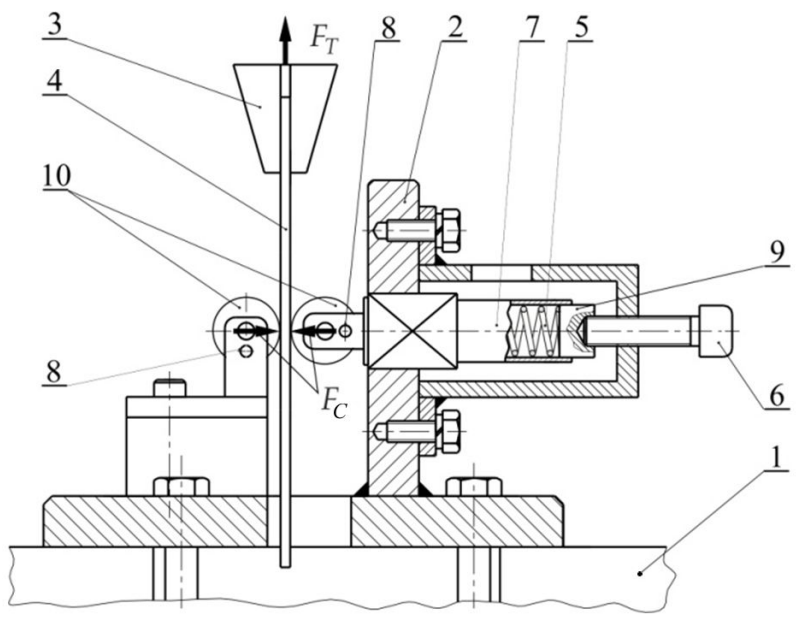

FiguRE 1. Schematic diagram of friction simulator: 1 - bottom grip of testing machine, 2 - base, 3 - upper grip of testing machine, 4 - specimen, 5 - spring, $6-$ bolt, 7 - mandrel, 8 - fixing pin, 9 - teflon insert, 10 - working rollers.

\begin{tabular}{lc}
\hline Oil type & $\begin{array}{c}\text { Kinematic viscosity } \\
\eta_{k}, \mathrm{~mm}^{2} / \mathrm{s}\end{array}$ \\
\hline Palm oil & 5.72 \\
Rape-seed oil & 4.45 \\
Engine oil SAE 10W-40 & 105.3 \\
Hydraulic oil L-HM 46 & 44.2 \\
Gear oil SAE 75W-85 & 64.6 \\
Machine oil L-AN 46 & 43.9 \\
\hline
\end{tabular}

TABLE 3. Kinematic viscosity of tested oils.

Prior to the friction test, both the specimens and countersamples were cleaned using acetone. The friction tests were carried out in both dry and lubricated conditions. Four types of synthetic oils and two types of vegetable oils with the addition of boric acid $\mathrm{H} 3 \mathrm{BO} 3$ were used in the lubricated condition. The types of vegetable oils and the amount of boric acid added (5 wt. \%) were selected based on the literature review [19, 28, 29]. The kinematic viscosity $\eta_{k}$ of tested oils provided by manufacturers were listed in Table 3

The nominal contact pressure for the contact between the flat specimen and cylindrical counter-sample was evaluated according to the formula [19]:

$$
p=\sqrt{\frac{0.418^{2} \cdot F_{C} \cdot E}{w \cdot R}}
$$

where $E$ is the Young's modulus of the specimen material and $R=10$ is the radius of the countersample.

In this paper, the radial basis function ANNs were used to model the friction in the SDT.

A typical radial network is a structure containing

- an input layer onto which signals described by the input vector $x$ are fed,

- a hidden layer with radial neurons,
- an output layer, which only sums the weights of signals from hidden neurons.

The RBF network analysed in the paper contains one hidden layer with radial neurons.

Based on the data available on changes in the value of the friction coefficient depending on the nominal pressure (Table 4), a network of two input neurons and one output neuron responsible for the COF value was adopted for the analysis. The values of the nominal pressure $p$ and kinematic viscosity $\eta_{k}$ of oils were taken as input data. Kinematic viscosity $\eta_{k}=0$ was assumed for dry friction conditions. The entire set of training data contained 42 datasets. From this set, $10 \%$ of the data was randomly selected and assigned to the validation set used for an independent control of the learning process. The $D$ data used in the network learning process were normalised using the min-max function:

$$
D^{\prime}=\frac{(D-\min )}{\max -\min }\left(N_{\max }-N_{\min }\right)+N_{\min }
$$

which transforms the domain of variables ( $\min , \max$ ) to a new interval $\left(N_{\min }=0, N_{\max }=1\right)$.

Those networks with a different number of radial neurons in the hidden layer (Fig. 2): 4, 8 and 12 were analysed in the research. The following parameters were used as basic indicators for assessing the quality of the ANN model:

- root mean square error RMSE:

$$
R M S E=\sqrt{\frac{1}{n} \sum_{i=1}^{n}\left|a_{j}-p_{j}\right|^{2}}
$$

- Pearson's correlation coefficient $R^{2}$ :

$$
R^{2}=1-\left(\frac{\sum_{i=1}^{n}\left(a_{j}-p_{j}\right)^{2}}{\sum_{i=1}^{n}\left(p_{j}\right)^{2}}\right)
$$

- standard deviation ratio (S.D. ratio) as a ratio of the standard deviation error and the standard deviation of the real values of the variable being explained.

Training the RBF network consists in determining the centres and deviations of radial neurons. The $\mathrm{k}$-means method was used for assigning the centres. The isotropic method was used to eliminate neu-ronal deviation. The deviation (identical for all neurons) is determined by the heuristic rule [30], taking into account the number of centres and the size of the space they occupy.

\section{Results And Discussion}

There are no precise guidelines in the literature for the selection of a neural network structure for the analysis of a specific problem. The number of neurons in the input and output layers is determined by the number of parameters presented in the network during the learning process. The selection of the number of 


\begin{tabular}{lcccccc}
\hline \multirow{2}{*}{$\begin{array}{l}\text { Friction } \\
\text { conditions }\end{array}$} & \multicolumn{5}{c}{ Coefficient of friction } \\
\cline { 2 - 7 } & $p=75 \mathrm{MPa}$ & $p=96 \mathrm{MPa}$ & $p=112 \mathrm{MPa}$ & $p=127 \mathrm{MPa}$ & $p=139 \mathrm{MPa}$ & $p=151 \mathrm{MPa}$ \\
\hline dry friction & 0.312 & 0.292 & 0.303 & 0.291 & 0.274 & 0.271 \\
L-AN 46 & 0.272 & 0.250 & 0.243 & 0.230 & 0.214 & 0.217 \\
L-HM 46 & 0.277 & 0.271 & 0.270 & 0.252 & 0.260 & 0.255 \\
SAE10W40 & 0.240 & 0.215 & 0.217 & 0.214 & 0.194 & 0.205 \\
SAE75W85 & 0.253 & 0.266 & 0.267 & 0.230 & 0.220 & 0.221 \\
palm oil & 0.226 & 0.241 & 0.233 & 0.223 & 0.229 & 0.216 \\
rape-seed oil & 0.263 & 0.257 & 0.254 & 0.237 & 0.221 & 0.212 \\
\hline
\end{tabular}

TABLE 4. The values of COFs determined at different nominal pressure $p$.

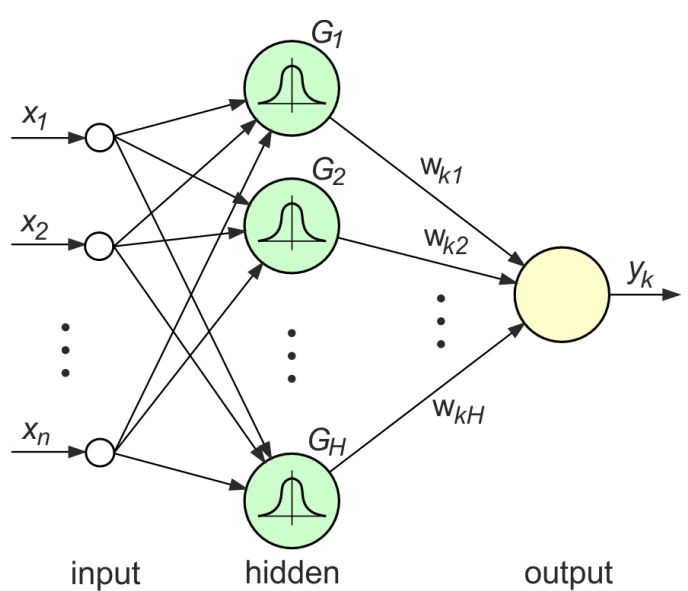

Figure 2. An RBF ANN with n-th inputs, H-th radial basis functions and one output.

neurons in the hidden layer depends on the complexity of the problem under consideration and it is difficult to define apriori. Therefore, the construction of three RBF ANNs with the number of neurons in the hidden layer equal to 8, 17 and 35 was initially assumed. Taking into account the limited amount of learning data, it was also assumed that the neural network would provide data prediction at the $R^{2}$ level of at least 0.95. The selected statistics of the networks that were analysed for the training set are presented in Table 5 . Increasing the number of neurons in the hidden layer clearly improved all the statistical parameters. The determination coefficient $R^{2}$ of the network with the largest number of hidden neurons RBF 2:2-35-1:1 met the assumed requirements.

Moreover, the value of the S.D. ratio proves a very good quality of the model. For a very good model, this measure ranges from 0 to 0.1 . If the value of the S.D. ratio is greater than one, the use of the constructed model is unjustified, because a more accurate estimate of the value of the explained variable is its arithmetic mean determined on the basis of the training set.

Response surfaces (Fig. 3) show the effect on the prediction of the output variable in adjusting two (independent) input variables. The RBF ANNs were utilised to study the influence of each of the two input variables on the coefficient of friction. The network architecture plays a clear role in the evaluation of the input parameters on the value of the COF. The response of the RBF 2:2-8-1:1 network is clearly bipolar. Low nominal pressure and low kinematic viscosity values result in a high value of the COF (Fig. 3a). If the input variables are large, the situation is the opposite. The response surfaces of the RBF 2:2-17-1:1 (Fig. 3p) and RBF 2:2-35-1:1 (Fig. 3c) networks are more similar. The concentration of the largest values of the coefficient of friction occurs for $\eta_{k}=0$ (dry friction) for average values of $\eta_{k}$ (gear oil SAE $75 \mathrm{~W}-85$ ) and average values of nominal pressure. The RBF 2:217-1:1 network model predicts values of the friction coefficient exceeding the lower range of the normalised $\mathrm{COF}$ value. Increasing the number of neurons in the hidden layer to 35 resulted in an improvement in the prediction, however, the network predicts negative values of COF (up to a normalised value of ${ }^{\smile 0.0617}$ ). The reason for this is the large fluctuations in the response surface associated with a relatively small number of training sets.

It is well known that increasing the value of nominal pressure intensifies the flattening of the roughness asperities of sheet metals by the surface of the tool. Under such conditions, there is a change in the topography of the sheet surface and the volume of the oil pockets. The oil pockets perform the role of oil reservoir and cause a decrease in the coefficient of friction. The as-received surface (Fig. 4a) exhibits a regular grain structure with a quite smooth surface of the grains. Flattening of the sheet surface was observed in both dry and lubricated conditions.

The main friction mechanism under a pressure of $75-112 \mathrm{MPa}$ and both dry and lubricated conditions was surface flattening (Figs. 4b, 4c). After increasing the pressure to the value of $139 \mathrm{MPa}$ and above, intensification of flattening and clear ploughing was observed (Fig. 4d) caused by the high pressure and, at the same time, there was adhesion of material of the plastically deformed surface asperities to the hard surface of the tool. Under these conditions, the sheet surface deteriorates as a result of the production of scratches on the surface of the sheet metal. In the case of lubricated conditions, flattening under the whole range of pressures applied was less intensive than in the case of the corresponding dry friction conditions. The flattening of surface asperities in the case of lu- 

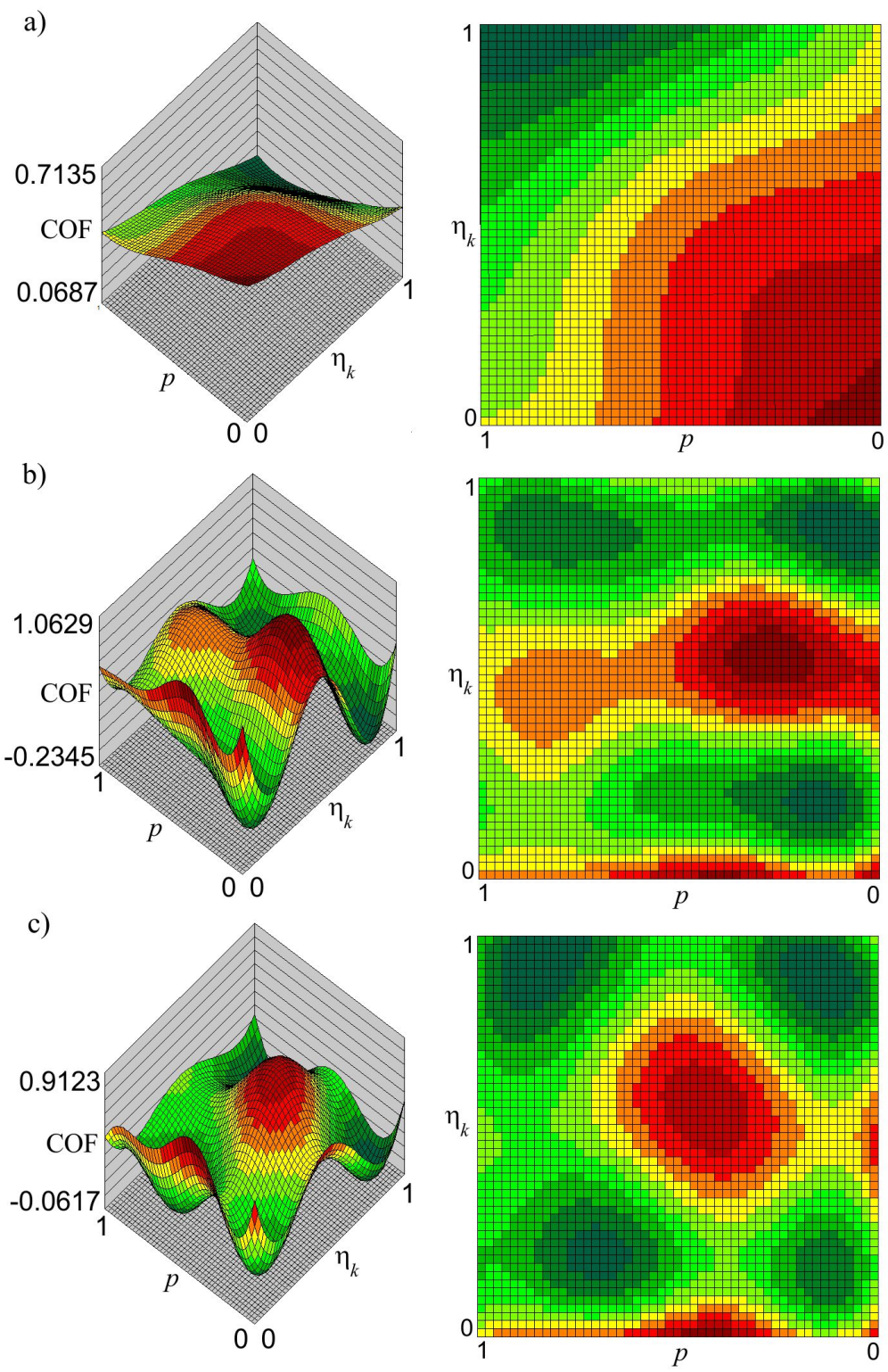

FiguRE 3. Response surfaces of the neural networks: a) RBF 2:2-8-1:1, b) RBF 2:2-17-1:1, c) RBF 2:2-35-1:1.

\begin{tabular}{lccc}
\hline Parameter & RBF 2:2-8-1:1 & RBF 2:2-17-1:1 & RBF 2:2-35-1:1 \\
\hline RMSE & 0.1608 & 0.0882 & 0.0125 \\
S.D. ratio & 0.7182 & 0.3940 & 0.0557 \\
Correlation $R^{2}$ & 0.6958 & 0.9190 & 0.9984 \\
\hline
\end{tabular}

TABLE 5. Selected statistics of the ANN's analysed. 


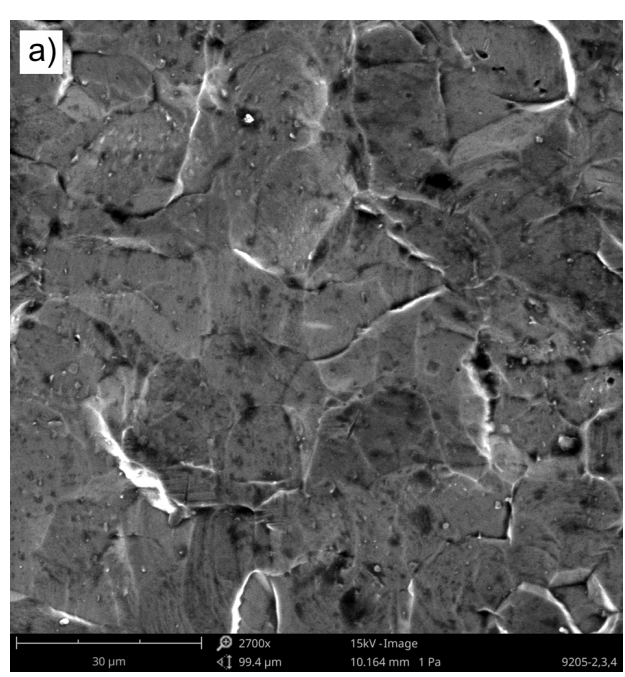

(A).

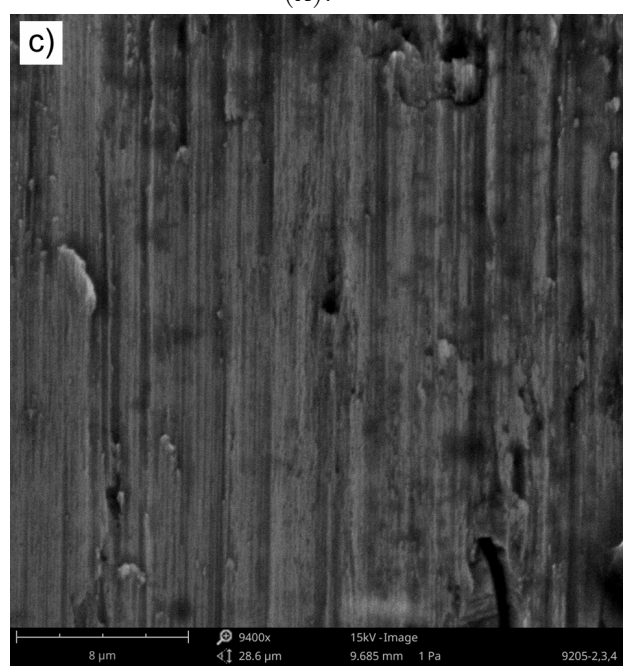

(C).

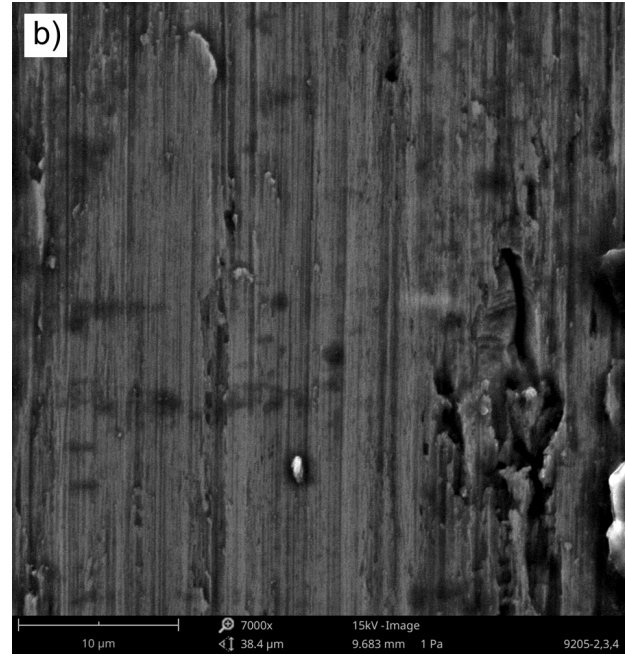

(в).

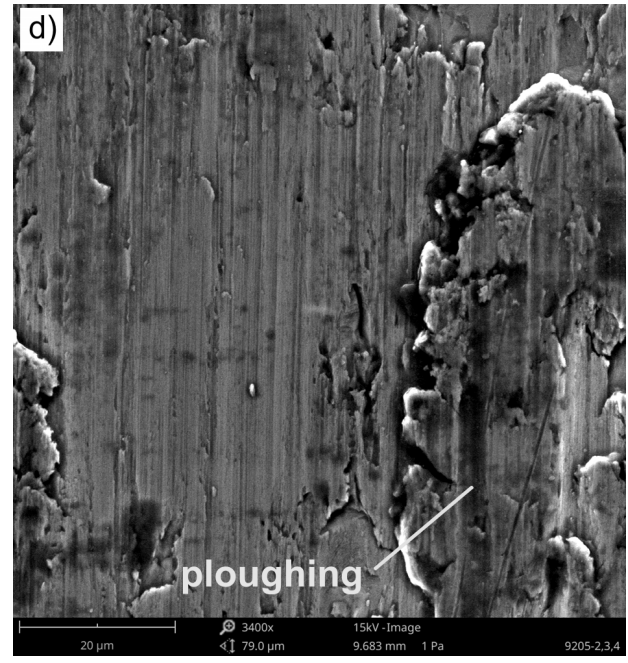

(D).

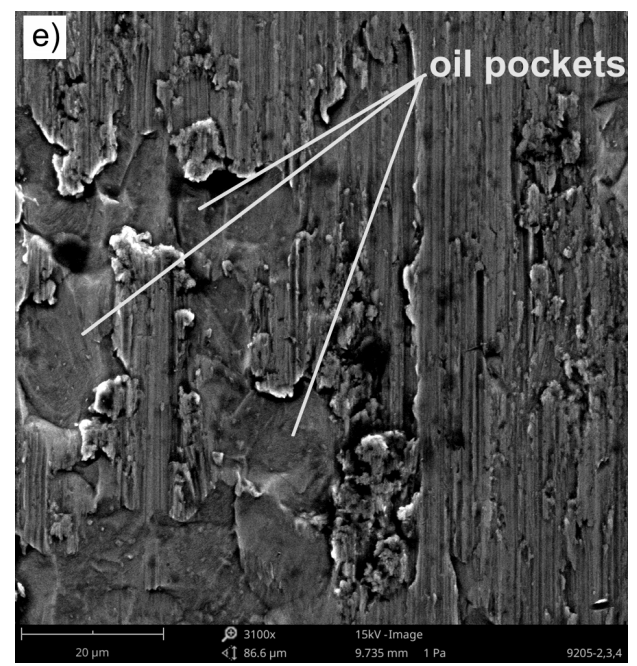

(E).

FigURE 4. SEM micrographs showing (a) the as-received surface in different magnifications, (b) the specimen surface tested in dry friction at $96 \mathrm{MPa}$, (c) the specimen surface tested in lubricated conditions using SAE 10W-40 engine oil at $96 \mathrm{MPa},(\mathrm{d})$ the specimen surface tested in dry friction at $139 \mathrm{MPa}$, (e) the specimen surface tested in dry friction at $112 \mathrm{MPa}$ under lubricated conditions using SAE 10W-40 engine oil. 


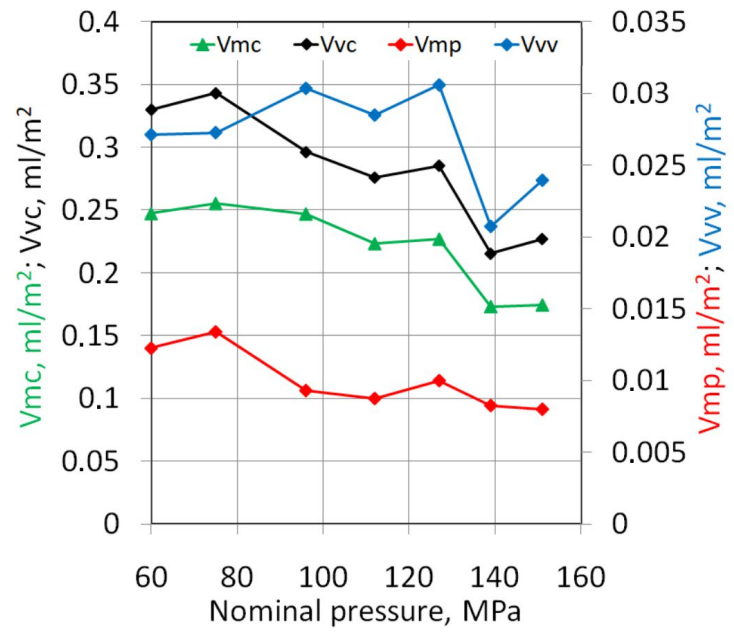

FigURE 5. Effect of nominal pressure on the variation in the functional volume parameters Vmc, Vvc, Vmp and Vvv under dry friction conditions.

bricated conditions causes an unfavourable reduction in the volume of the oil pockets (Fig. 4e).

With an increase in nominal pressure, there is a clear trend to a decreasing value of the core material volume Vmc, the core void volume Vvc and peak material volume Vmp (Fig. 5). An increase in the peak material volume and the dale void volume ( $\mathrm{Vvv}$ ) above a pressure of $139 \mathrm{MPa}$ can be related to the ploughing of the sheet surface (Fig. 4d). Under these conditions, core material volume Vvc and core void volume Vmc stabilise. Scratching of deep grooves increases the friction force. Moreover, deep longitudinal grooves, being the open oil pockets, are able to assure sufficient lubricant pressure [31. The asperities of the roughness deform until the resulting bearing surface is able to transmit the pressure. When load is applied, the asperity features are deformed until the increased bearing area is sufficient to support the applied load.

\section{Conclusions}

In this paper, the RBF ANNs were used to investigate the interaction between nominal pressure and kinematic viscosity of the lubricant and their influence on the value of the coefficient of friction of Ti-6Al-4V titanium alloy tested in the strip drawing test. The following conclusions are drawn from the research:

- the value of the coefficient of friction was between 0.194 and 0.312 , depending on the lubrication conditions,

- over the entire range of the nominal pressures applied, SAE 10W-40 engine oil ensured the most effective reduction of the $\mathrm{COF}$,

- the neural network with the highest value of the coefficient of determination was RBF 2:2-35-1:1,

- an increase in the number of radial neurons in the hidden layer caused an increase in the value of the determination coefficient and a reduction in the
S.D. ratio as compared to $\mathrm{RBF} 2: 2-17-1: 1$ and $\mathrm{RBF}$ $2: 2-8-1: 1$,

- the COF value was the highest for average values of both the nominal pressure and kinematic viscosity,

- in the range of pressure between 75 and $112 \mathrm{MPa}$, the flattening mechanism dominates in both dry and lubricated conditions,

- an intensive flattening of the surface asperities of Ti-6Al-4V under lubricated conditions begins to reduce the oil pockets,

- an increase of nominal pressure during the strip drawing tests of $\mathrm{Ti}-6 \mathrm{Al}-4 \mathrm{~V}$ causes a trend to a reduction of core material volume, core void volume and peak material volume.

\section{REFERENCES}

[1] C. V. Nielsen, N. Bay. Review of friction modeling in metal forming processes. Journal of Materials Processing Technology 255:234 - 241, 2018. https://doi.org/10.1016/j.jmatprotec.2017.12.023

[2] T. Trzepieciński, R. Fejkiel. On the influence of deformation of deep drawing quality steel sheet on surface topography and friction. Tribology International 115:78 88, 2017. https://doi.org/10.1016/j.triboint.2017.05.007

[3] J. Shen, C. Wu, L. Zhang. Effects of sliding speed and lubrication on the tribological behaviour of stainless steel. The International Journal of Advanced Manufacturing Technology 94:341 - 350, 2018. https://doi.org/10.1007/s00170-017-0907-8.

[4] T. Trzepieciński, H. G. Lemu. Frictional conditions of AA5251 aluminium alloy sheets using drawbead simulator tests and numerical methods. Strojniški vestnik - Journal of Mechanical Engineering 60(1):51 60, 2014. https://doi.org/10.5545/sv-jme.2013.1310

[5] J. Jaworski, T. Trzepieciński. Research on durability of turning tools made of low-alloy high-speed steels. Kovove Materialy - Metallic Materials 54:17 - 25, 2016. https://doi.org/10.4149/km_2016_1_17.

[6] A. L. Yerokhin, X. Nie, A. Leyland, A. Matthews. Characterisation of oxide films produced by plasma electrolytic oxidation of a Ti-6Al-4V alloy. Surface and Coatings Technology 130(2):195 - 206, 2000. https://doi.org/10.1016/S0257-8972(00)00719-2

[7] M. Fellah, M. Labaiz, O. Assala, et al. Tribological behavior of Ti-6Al-4V and Ti-6Al-7Nb alloys for total hip prosthesis. Advances in Tribology 2014:1 - 13, 2014. https://doi.org/10.1155/2014/451387.

[8] S. Kaur, K. H. Ghadirinejad, R. H. Oskouei. An overview on the tribological performance of titanium alloys with surface modifications for biomedical applications. Lubricants 7:65, 2019. https://doi.org/10.3390/lubricants7080065

[9] J. Cao, R. Zhou, Q. Wang, Z. C. Xia. Strip-oncylinder test apparatus for die wear characterization. CIRP Annals - Manufacturing Technology 58(1):251 254, 2009. https://doi.org/10.1016/j.cirp.2009.03.098 
[10] I. Masters, D. K. Williams, R. Roy. Friction behaviour in strip draw test of pre-stretched high strength automotive aluminium alloys. International Journal of Machine Tools and Manufacture 73:17 - 24, 2013. https://doi.org/10.1016/j.ijmachtools.2013.05.002.

[11] V. Prakash, D. R. Kumar. Performance evaluation of bio-lubricants in strip drawing and deep drawing of an aluminium alloy. Advances in Materials and Processing Technologies 6:1 - 14, 2020. https://doi.org/10.1080/2374068X.2020.1838134.

[12] L. Figueiredo, A. Ramalho, M. C. Oliveira, L. Menezes. Experimental study of friction in sheet metal forming. Wear 271(9):1651 - 1657, 2011. https://doi.org/10.1016/j.wear.2011.02.020

[13] M. R. Lovell, Z. Deng. Characterization of interfacial friction in coated sheet steels: influence of stamping process parameters and wear mechanisms. Tribology International 35(2):85 - 95, 2002. https://doi.org/10.1016/S0301-679X(01)00097-4.

[14] M. Ciavarella, J. Joe, A. Papangelo, J. Barber. The role of adhesion in contact mechanics. Journal of the Royal Society Interface 16:20180738, 2019. https://doi.org/10.1098/rsif.2018.0738

[15] Y. Fan, Z. K. Li, J. Liu. Simulation of surface contact process and study of friction and wear mechanisms. Advanced Materials Research 562 - 564:540 - 543, 2012. https://doi.org/10.4028/www.scientific.net/AMR.562564.540 .

[16] J. Hol, J. H. Wiebenga, B. Carleer. Friction and lubrication modelling in sheet metal forming: Influence of lubrication amount, tool roughness and sheet coating on product quality. Journal of Physics: Conference Series 896:012026, 2017. https://doi.org/10.1088/1742-6596/896/1/012026

[17] F. Sgarabotto, A. Ghiotti. Frictional behaviour of environmentally friendly lubricants for sheet metal forming processes. Key Engineering Materials 504 506:537 - 542, 2012.

https://doi.org/10.4028/www.scientific.net/KEM.504506.537.

[18] S. Weidel, U. Engel, M. Merklein, M. Geiger. Basic investigations on boundary lubrication in metal forming processes by in situ observation of the real contact area. Production Engineering 4:107 - 114, 2009. https://doi.org/10.1007/s11740-009-0198-5

[19] T. Trzepieciński. Tribological performance of environmentally friendly bio-degradable lubricants based on a combination of boric acid and bio-based oils. Materials 13:3892, 2020. https://doi.org/10.3390/ma13173892.

[20] M. Lüchinger, I. Velkavrh, K. Kern, et al. Development of a constitutive model for friction in bulk metal forming. Lubricants 6:42, 2018. https://doi.org/10.3390/lubricants6020042
[21] Y. Huang, S. Gilmour, K. Mylona, P. Goos. Optimal design of experiments for nonlinear response surface models. Journal of the Royal Statistical Society Series C - Applied Statistics 68(3):623 - 640, 2019. https://doi.org/10.1111/rssc.12313

[22] S. Crino, D. Brown. Global optimization with multivariate adaptive regression splines. IEEE Transactions on Systems, Man, and Cybernetics Part B, Cybernetics 37(2):333 - 340, 2007. https://doi.org/10.1109/TSMCB.2006.883430

[23] M. Chwalina. Demand modelling in telecommunications comparison of standard statistical methods and approaches based up-on artificial intelligence methods including neural networks. Acta Polytechnica 49(2):48 - 52, 2009. https://doi.org/10.14311/1121.

[24] Y. L. Karnavas, A. Vairis. Modelling of frictional phenomena using neural networks: friction coefficient estimation. In Proc. Of the IASTED Int. Conf. Applied Simulation and Modelling (ASM 2011), pp. $54-58$. Crete, Greece, 2011.

[25] H. Cetinel. The artificial neural network based prediction of friction properties of $\mathrm{Al} 2 \mathrm{O} 3-\mathrm{TiO} 2$ coatings. Industrial Lubrication and Tribology 64(5):288 - 293, 2012. https://doi.org/10.1108/00368791211249674

[26] Rustam, A. Y. Gunawan, M. T. A. P. Kresnowati. Artificial neural network approach for the identification of clove buds origin based on metabolites composition. Acta Polytechnica 60(5):440 - 447, 2020. https://doi.org/10.14311/AP.2020.60.0440.

[27] I. Bukovský, M. Kolovratník. A neural network model for predicting NOx at the Mělník 1 coal-powder power plant. Acta Polytechnica 52(3):17 - 22, 2012. https://doi.org/10.14311/1538.

[28] A. Bahari, R. Lewis, T. Slatter. Friction and wear phenomena of vegetable oil-based lubricants with additives at severe sliding wear conditions. Tribology Transactions 61(2):207 - 219, 2018. https://doi.org/10.1080/10402004.2017.1290858

[29] M. Fan, L. Ma, C. Zhang, et al. Biobased green lubricants: Physicochemical, tribological and toxicological properties of fatty acid ionic liquids. Tribology Transactions 61(2):195 - 206, 2018. https://doi.org/10.1080/10402004.2017.1290856

[30] S. Haykin. Neural Networks: A Comprehensive Foundation. Macmillan Publishing, New York, 1994.

[31] C. Wang, B. Guo, D. Shan. Friction related size-effect in microforming - A review. Manufacturing Review 1:23, 2014. https://doi.org/10.1051/mfreview/2014022 